\title{
Índice de vegetação por diferença normalizada (NDVI) no médio curso do Rio Ceará
}

A cobertura vegetal é um componente fundamental em regiões de bacia hidrográfica, principalmente em áreas de proteção ambiental (APP), que, cada vez mais, sofrem com a ocupação desordenada e o uso intensivo dos recursos naturais. O objetivo deste artigo é apresentar uma análise temporal da cobertura vegetal no médio curso do rio Ceará, destacando as diferentes formas de uso e ocupação do solo que constituem a paisagem local. Com base na caracterização do Índice Vegetação por Diferença Normalizada (NDVI), avaliou-se o estado geral de degradação ambiental em um recorte espacial que abrange as comunidades indígenas locais. Para isso, aplicou-se o método de estudo de caso, com base na abordagem geossistêmica, e utilizou-se ferramentas de sensoriamento remoto. 0 estudo gerou mapas de uso e ocupação do solo, referentes ao ano de 2017, e de índice, dos anos de 1985, 1996, 2006 e 2015. Os resultados mostraram um cenário de crescente desmatamento e manifestação dos processos erosivos, que culminaram na degradação da Área de Preservação Permanente (APP). A avaliação da dinâmica da paisagem revelou que a maior parte da região não possui cobertura nativa. No entanto, cabe destacar que, nos arredores das comunidades indígenas, prevalece a cobertura vegetal em melhor estado de conservação. Na análise espaço-temporal das imagens de 1985, 1996, 2006, 2015, evidencia-se o aumento das áreas degradadas que apresentam menor índice de vegetação no ano de 2015. Assim, percebe-se a necessidade da aplicação de estratégias de gestão ambiental capazes de reverter as ações impactantes e preservar as áreas que ainda conservam valores ecológicos e socioculturais.

Palavras-chave: Degradação da Cobertura Vegetal; Análise Ambiental; Sensoriamento Remoto.

\section{Normalized Difference Vegetation Index (NDVI) in the middle course of the Ceará River}

\begin{abstract}
Vegetation cover is a key component in watershed areas, especially in areas of environmental protection (APP), which are increasingly suffering from disordered occupation and the intensive use of natural resources. The objective of this article is to present a time analysis on the vegetation cover of the soil in the middle course of the Ceará River, highlighting the different forms of soil use and occupation that constitute the local landscape. Based on the characterization of the Normalized Difference Vegetation Index (NDVI), the general state of environmental degradation was evaluated in a spatial cut that covers the local indigenous communities. For this, the case study method was applied, based on the geosystemic approach, using tools of remote sensing. The study generated maps of soil use and occupation, referring to the year 2017, and index maps of the years of 1985, 1996, 2006 and 2015. The results showed a scenario of increasing deforestation and manifestation of the erosive processes, culminating in the degradation of the Permanent Preservation Area (APP). The evaluation of the landscape dynamics revealed that most of the region does not have native cover as; however, it is worth highlighting that in the surroundings of the indigenous communities, the vegetation cover prevails in a better state of conservation. In the space-time analysis of the images of 1985, 1996, 2006, 2015, it is evident the increase of the degraded areas presenting a lower index of vegetation in the year 2015. It became clear the need to apply environmental management strategies able to reverse impacting actions and to preserve areas that still add ecological and socio-cultural values.
\end{abstract}

Keywords: Vegetation Covers Degradation; Environmental Analysis; Remote Sensing.

Topic: Desenvolvimento, Sustentabilidade e Meio Ambiente

Reviewed anonymously in the process of blind peer.
Received: 02/12/2018

Approved: 26/01/2019
Silvia Juliane Ventura

Universidade Federal do Ceará, Brasil

http://lattes.cnpq.br/6503245001940199

sventuraa@gmail.com

Lúcio Correia Miranda (iD)

Universidade Federal do Pará, Brasil

http://lattes.cnpq.br/3405266586655153

http://orcid.org/0000-0002-3592-9376

Icmiranda-ufc@hotmail.com

Edson Vicente da Silva (iD)

Universidade Federal do Ceará, Brasil

http://lattes.cnpq.br/3354228537186786

http://orcid.org/0000-0001-5688-750X

cauceara@gmail.com

\section{Referencing this:}

VENTURA, S. J.; MIRANDA, L. C.; SILVA, E. V.. Índice de vegetação por diferença normalizada (NDVI) no médio curso do Rio Ceará. Revista Ibero Americana de Ciências Ambientais, v.10, n.1, p.252-261, 2019. DOI: http://doi.org/10.6008/CBPC2179-6858.2019.001.0021 


\section{INTRODUÇÃO}

A bacia hidrográfica se constitui como unidade de recorte espacial para os estudos ambientais, e isso tem sido cada vez mais empregado nas estratégias de gestão ambiental. Como compartimento ambiental, ela abrange toda a área de captação natural da água da chuva para o canal principal. É um sistema aberto que recebe energia por meio de agentes climáticos e perde energia por meio do deflúvio, podendo ser descrita "em termos de variáveis interdependentes, que oscilam em torno de um padrão e, mesmo quando perturbadas por ações antrópicas, encontram-se em equilíbrio dinâmico" (LIMA et al., 2000).

Segundo Barrella et al. (2001), a bacia hidrográfica pode ser definida, também, como um conjunto de terras drenadas por um rio e seus afluentes, formadas nas regiões mais altas do relevo por divisores de água, onde as águas das chuvas escoam superficialmente e dão origem a riachos e rios ou infiltram no solo e formam nascentes e lençóis freáticos.

A Política Nacional de Recursos Hídricos, por meio da Lei Federal o 9.433, de 8 de janeiro de 1997, definiu a bacia hidrográfica como unidade territorial para a implementação e atuação do Sistema Nacional de Gerenciamento de Recursos Hídricos. Essa visão tornou importante a adoção de bacias hidrográficas como objeto de pesquisas e análises ambientais e fez com que esses estudos ficassem mais populares entre profissionais das áreas relacionadas, visto que os fatores físicos, biológicos, econômicos e sociais que integram a área da bacia influenciam a qualidade dos sistemas fluviais.

A intervenção humana na vegetação e, principalmente, na mata ciliar é um dos fatores que influenciam a qualidade dos sistemas fluviais, pois desrespeita as normativas legais que direcionam medidas de gestão em que só se permite usos múltiplos dessas áreas quando se tem um plano de manejo aprovado pelo órgão ambiental competente, embora, mesmo assim, seja causada uma série de danos ambientais (BELLUTA et al., 2011). O principal instrumento de manejo de bacias hidrográficas previsto em lei é o Novo Código Florestal, de 2012, criado pela Lei Federal no 12.651/2012, que, em seu artigo 30, parágrafo II, e artigo 40, refere-se às áreas de preservação permanente, em especial, à faixa da mata ciliar (BRASIL, 2012).

A proteção das áreas de preservação permanente (APP) é de fundamental importância na gestão de bacias hidrográficas, pois contribui para a estabilidade dos ciclos hidrológicos e biogeoquímicos e proporciona melhores condições de sustentabilidade à agricultura e a outros processos de exploração (RODRIGUES et al., 2004).

A manutenção de áreas naturais como as APP, especialmente em áreas rurais, é essencial, uma vez que há uma percepção inadequada de que as terras com vegetação nativa representam áreas não produtivas, que geram custo sem retorno para o produtor, embora sejam fundamentais para manter a produtividade em sistemas agropecuários, devido, principalmente, à sua influência direta na produção e na conservação da água, da biodiversidade, do solo, na manutenção de abrigos para agentes polinizadores, dispersores e inimigos naturais de pragas das culturas das próprias propriedades (SILVA et al., 2011).

A significativa diminuição da cobertura vegetal, particularmente das áreas de preservação permanente (APP), como a vegetação ciliar, ou áreas de várzeas, além de expor as terras aos processos de 
erosão, tem contribuído para a poluição das águas, principalmente com resíduos orgânicos e pesticidas (PIGOSSO et al., 2009).

Essas regiões sempre foram de grande relevância para a humanidade e é certo que essa relevância pode ser ainda maior para as futuras gerações, em especial em razão do grande impacto que têm sofrido e também por lhes ser atribuída a função de conservar a qualidade da água. Esse recurso deve ser avaliado tanto com relação a seus aspectos ecológicos quanto aos econômicos e sociais, pois, apesar da importância da vegetação ciliar, a sua devastação vem se agravando em diversas regiões, sobretudo na região do semiárido, principalmente em função das atividades agropastoris.

O objetivo deste estudo foi apresentar uma análise sobre o uso e a ocupação do solo, destacando os impactos ambientais relacionados à bacia hidrográfica da região metropolitana de Fortaleza, especificamente do médio curso do rio Ceará, no qual, ao longo dos anos, têm sido realizados diversos estudos, principalmente no seu baixo curso, que tratam especificamente do estuário, com destaque para o desmatamento, o uso e a ocupação dos manguezais (MARINHAS et al., 2002; PAULA, 2008; MORAES et al., 2015; MARTINS et al., 2017).

As análises mais específicas sobre o médio curso do rio Ceará ainda são incipientes, o que torna esta pesquisa necessária, uma vez que, na planície fluvial, encontram-se instaladas diversas empresas que realizam, sem o planejamento adequado, atividades impactantes, como: desmatamento da vegetação da mata ciliar, extração de areia para construção civil, emissão de resíduos sólidos domésticos e industriais sem o devido tratamento.

Para alcançar os objetivos propostos, as técnicas de sensoriamento remoto e geoprocessamento nas análises ambientais foram de fundamental importância, pois, na atualidade, vêm se tornando ferramentas cada vez mais utilizadas nas diversas áreas de pesquisa, como estudos de análises integradas da paisagem, pesquisas sobre fragilidade ambiental, análises de processos de erosão, cobertura vegetal, entre outros (BASTOS et al., 2012; ZANZARINE et al., 2013; BATISTA, 2015; RIBEIRO et al., 2017), uma vez que fornecem informações bastante significativas com rapidez, eficácia e credibilidade nas análises que abrangem os processos de degradação da vegetação natural, fiscalização dos recursos ambientais e desenvolvimento de políticas conservacionistas.

\section{METODOLOGIA}

O estudo em questão se desenvolveu em um dos trechos do médio curso do rio Ceará, situado no setor oriental do município de Caucaia, que abrange uma extensão territorial de $64,55 \mathrm{~km}^{2}$ e localiza-se na zona UTM 24S, especificamente entre as coordenadas Norte 9572000 e 9584585,62 e Este 520664,8 e 537033,21 , conforme se observa na figura 1 . O rio Ceará, que nasce em Maranguape, percorre o município de Caucaia em sua maior extensão, dirigindo-se de sudoeste a nordeste, e sua foz fica a noroeste de Fortaleza, no oceano Atlântico (MEDEIROS, 2012; IBGE, 2018). 


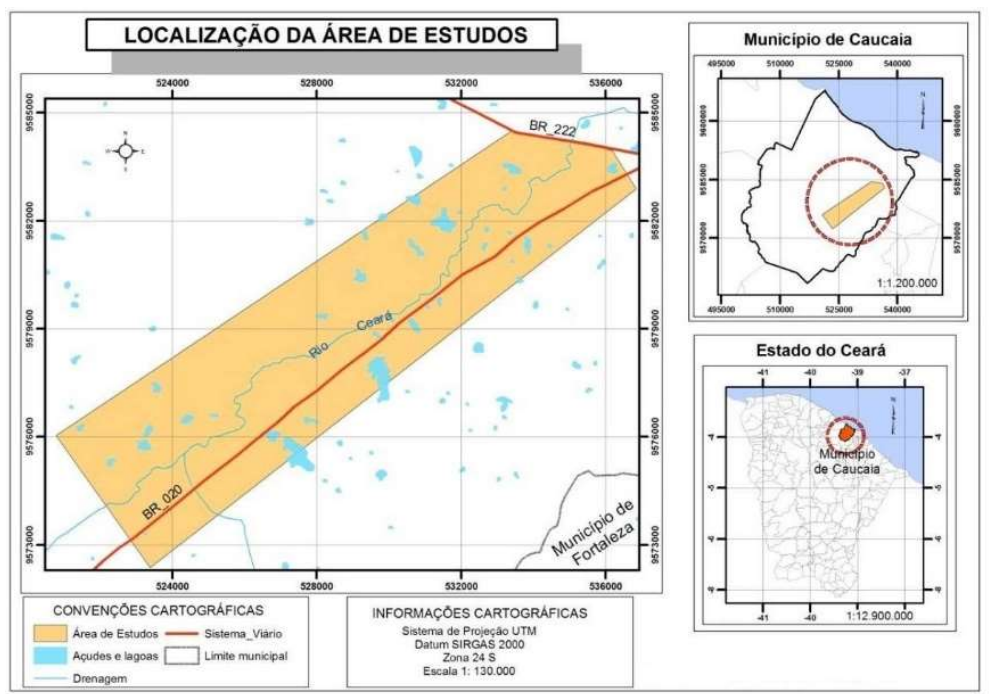

Figura 1: Mapa da localização da área de estudos: Médio Curso do Rio Ceará.

Segundo a classificação de Köppen, o clima de Caucaia é 'do tipo Aw'- tropical chuvoso, quente e úmido, com estação chuvosa concentrada no verão e outono'. Já os ventos, na localidade, apresentam direção predominantemente leste. E, durante o verão e o outono, a interferência da Convergência Intertropical (CIT) dá início à estação chuvosa, o que resulta numa mudança brusca na direção dos ventos que convergem para sudeste. A velocidade média anual dos ventos é de 3,6 m/s (TURETTA et al., 2007; IPECE, 2018).

De acordo com Souza (2005) e Medeiros et al. (2012), o município de Caucaia apresenta características geológicas com coberturas sedimentares representadas pela formação barreiras, coberturas coluviais-eluviais, depósitos eólicos (paleodunas e dunas móveis), depósitos flúvio-aluvionares e depósitos flúvio-marinhos.

As características do solo apresentam as seguintes classes: argissolos vermelhos, amarelos distróficos, argissolos vermelho-amarelos eutróficos, gleissolos sálicos sódicos, luvissolos crômicos, neossolos flúvicos eutróficos, neossolos litólicos eutróficos, neossolos quartzarênicos, planossolos háplicos eutróficos e vertissolos (IPECE, 2015).

A metodologia aplicada na pesquisa foi o método de estudo de caso, no qual se utilizou uma abordagem geossistêmica. Para o alcance dos objetivos propostos, os procedimentos metodológicos subdividiram-se em três etapas: levantamento bibliográfico, realizado nas bibliotecas e órgãos públicos, dentre os quais se destacam a Superintendência Estadual do Meio Ambiente (SEMACE), a Secretaria Municipal de Meio Ambiente e Controle Urbano (SEMAN) e o Instituto Brasileiro de Geografia e Estatística (IBGE); ii) levantamento cartográfico, efetivado no sites dos órgãos nacionais e internacionais, especialmente do Instituto Nacional de Pesquisas Espaciais e do Serviço Geológico Americano, como fontes de aquisição das imagens de Satélite Landsat; e iii) processamento de imagens de satélites, realizado no ArcGIS 10.5.

As imagens utilizadas foram do Landsat, sensor TM, correspondentes aos anos de 1985, 1996 e 2006, e do sensor OLI, dos anos de 2015 e 2017. O processamento para a geração do índice de vegetação se baseou na utilização das bandas do infravermelho próximo (NIR) e a banda do vermelho (RED), aplicadas na equação 
NDVI $=\frac{\text { NIR-RED }}{\text { NIR+RED }}$, conforme as aplicação de Liu (2006). Foram gerados o mapa de uso e ocupação do solo para o ano de 2017, na escala de 1:100.00, e o índice de vegetação por diferença normalizada (NDVI), no intervalo de 1985 à 2015, na escala de 1:150.000, com base nas orientações de Ferreira et al. (2008) e Liu (2006).

Segundo Liu (2006), o NDVI demostra o vigor da vegetação, pois se constitui de valores que variam entre -1 a +1 , sendo que os valores negativos representam nuvens, espelho da água, afloramento rochoso, aglomerados populacionais (edificações) e, em geral, solos desprovidos de qualquer cobertura vegetal; e os valores positivos denotam a presença da vegetação, porque, quanto maior for o valor, mais densa é a cobertura vegetal ou a superfície está coberta por vegetação em pleno vigor do crescimento.

Para essa análise, as imagens utilizadas foram das séries Landsat 5, sensor TM (Bandas 4 e 3) e Landsat 8, sensor OLI (Bandas 5 e 4), respectivamente, com resolução espacial de 30 metros, ambas as imagens obtidas no site do Serviço Geológico Americano (USGS), como se observa na tabela 1. O mapa de uso e ocupação do solo foi elaborado aplicando-se a composição R4G3B2 do Landsat 8, para identificar os diferentes tipos de uso e o estado de conservação da cobertura vegetal no médio curso do rio Ceará.

Tabela 1: Características e lista de imagens do médio curso do rio Ceará.

\begin{tabular}{|l|l|l|l|l|l|l|}
\hline Data & Satélite & $\begin{array}{l}\text { Instrumentos } \\
\text { sensores }\end{array}$ & Banda & $\begin{array}{l}\text { Órbita } \\
\text { Ponto }\end{array}$ & $\begin{array}{l}\text { Resolução } \\
\text { espacial }\end{array}$ & $\begin{array}{l}\text { Total pluviométrico } \\
\text { mensal }\end{array}$ \\
\hline $20 / 07 / 1985$ & Landsat 5 & TM & 3 (red) e 4 (NIR) & $217 / 63$ & 30 metros & $0 \mathrm{~mm}$ \\
\hline $31 / 05 / 1996$ & Landsat 5 & $\mathrm{M}$ & $3(\mathrm{red})$ e 4 (NIR) & $217 / 63$ & 30 metros & $268,2 \mathrm{~mm}$ \\
\hline $14 / 07 / 2006$ & Landsat 5 & TM & $3(\mathrm{red}$ e 4 (NIR) & $217 / 63$ & 30 metros & $17 \mathrm{~mm}$ \\
\hline $08 / 08 / 2015$ & Landsat 8 & OLI/TIRS & $4(\mathrm{red}$ e 5 (NIR) & $217 / 63$ & 30 metros & $10,4 \mathrm{~mm}$ \\
\hline 20/04/2017 & Landsat 8 & OLI/TIRS & 4 (red) e 5 (NIR) & $217 / 63$ & 30 metros & $415 \mathrm{~mm}$ \\
\hline
\end{tabular}

Fonte: Fundação Cearense de meteorologia e recursos hídricos (FUNCEME) e Serviço Geológico Americano (USGS).

\section{RESULTADOS E DISCUSSÃO}

A destruição da vegetação é um dos pontos críticos da degradação no médio curso do rio Ceará, sendo o desmatamento um dos seus principais causadores, uma vez que as áreas desmatadas correspondem a $29 \mathrm{~km}^{2}$, como podemos verificar no quadro 1, e a área de vegetação conservada é de 15,81 km². De acordo com Ribeiro et al., (2015) o desmatamento é uma das causas principais de degradação no mundo. O quadro 1 mostra as condições atuais.

Quadro 1: Classes de uso e ocupação do solo (2017).

\begin{tabular}{|l|l|}
\hline USO E OCUPAÇÃO DO SOLO & $\mathbf{k m}^{\mathbf{2}}$ \\
\hline Classes de uso & 0.41 \\
\hline Mineração & 1.51 \\
\hline Hidrografia & 6.94 \\
\hline Urbana & 14.77 \\
\hline Agropecuária & 15.81 \\
\hline Vegetação & 24.99 \\
\hline Solo Exposto & \\
\hline
\end{tabular}

A ocupação no médio curso do rio Ceará é diversificada e apresenta áreas bem povoadas ou, ainda, com agricultura, mineração e indústria (fábricas de telhas e tijolos), que são as principais atividades econômicas do local. No mapa de uso e ocupação do solo (figura 2), é possível visualizar essas características. 
Na região, existe grande área com solo exposto e áreas de preservação permanente (APP) escassas. Segundo Vieira et al. (2013), em um levantamento do uso e da cobertura do solo da região semiárida do Brasil, 57\% do território do Nordeste brasileiro representa áreas antropizadas, que antes eram ocupadas por caatinga, o que revela uma acelerada degradação da mata nativa.

A vegetação conservada da região se caracteriza como Complexo Vegetacional de Zona Litorânea, com espécies de Mata Atlântica, Cerrado, Caatinga e tem grande importância econômica ecológica e botânica por sua característica ecotonal (FERNANDES, 1990; CASTRO et al., 2012). Segundo Júnior et al. (2014) e Pereira Júnior et al. (2012), a Caatinga é um bioma com grande riqueza em recursos genéticos, devido a sua alta biodiversidade, quando comparada a outras regiões semiáridas no mundo.

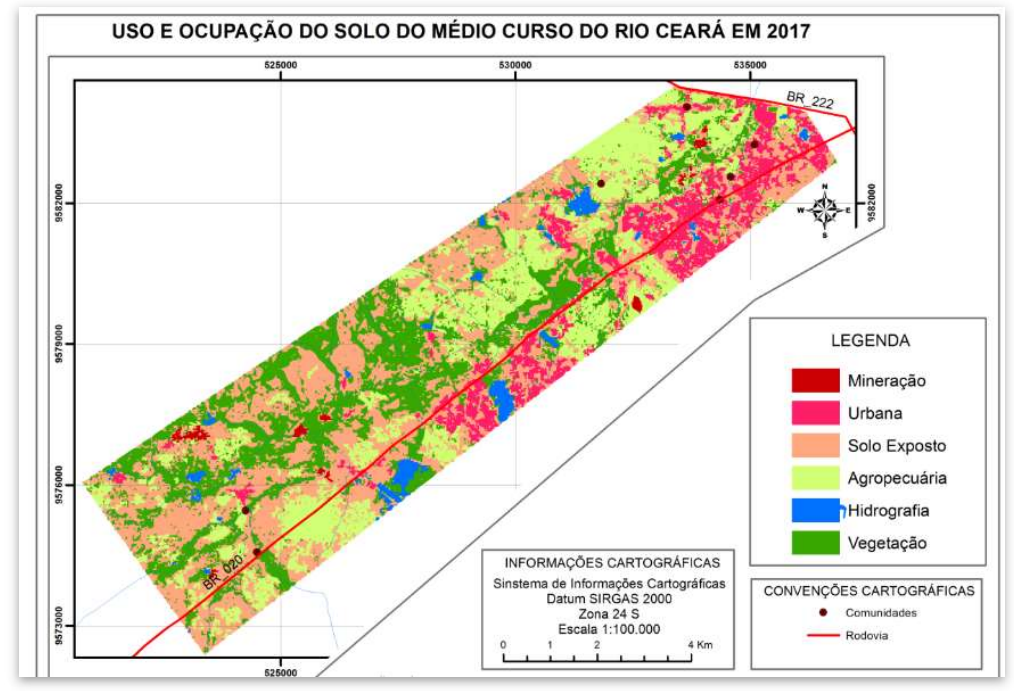

Figura 2: Uso e ocupação do solo do Médio Curso do Rio Ceará.

A produção agrícola é pequena e de subsistência - produção de alimentos, culturas temporárias, algumas culturas permanentes -, com o sistema agrossivilpastoril. Entre as culturas da região, encontramos: feijão, abacate, batata-doce, fava, limão, sorgo, maxixe, gergelim, abobora e algumas hortaliças (IBGE, 2018). A criação de animais também é pequena e difícil nos períodos de seca, no entanto, moradores relatam ser uma importante atividade na complementação da renda, pois uma pequena parte dos produtos é vendida em feiras. A produção de bovinos da localidade é a mais representativa no município de Caucaia, mesmo que nos últimos anos a pecuária no Ceará tenha apresentado recuo, devido às condições meteorológicas adversas (IBGE, 2018; IPECE, 2018).

Apesar de toda a importância dessa região, a exploração dos recursos é contínua. A maioria dos moradores evita falar sobre o assunto, mas alguns informaram o uso da vegetação como lenha para abastecer as fábricas de tijolos. Existe, também, a extração de areia nas margens do rio e de argila, como retrata a figura 3, atividade que ocorre, muitas vezes, de forma ilegal e é justificada pela dificuldade financeira, pois representa uma das fontes de renda para a sobrevivência dos habitantes. 


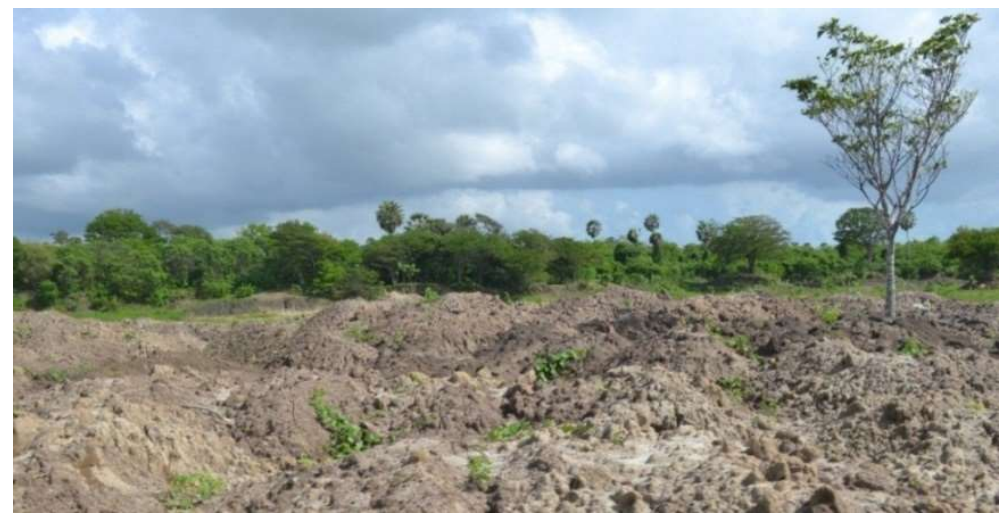

Figura 3: Área de extração de argila na comunidade Lameirão.

Para que esses processos sejam estabilizados e ocorram de forma sustentável, é preciso um longo trabalho de educação ambiental, fiscalização e aplicação das leis ambientais. Quanto a isso, devemos destacar a Lei no 12.651, de 2012, que estabelece a área rural consolidada em que a ocupação humana em área de instalação de imóvel rural, que tenha ocorrido antes de 22 de julho de 2008, deve ser consolidada mesmo que seja uma área de preservação permanente - dependendo das atividades ali exercidas, é determinada uma porcentagem para a preservação (GASS et al., 2016).

Quanto ao extrativismo vegetal, destaca-se a exploração de folhas de carnaúba para a produção de fibras e cera, coleta de caju para a produção de castanhas, além da extração de madeira para a produção de lenha, cercas e carvão. No mapa de índice de vegetação por diferença normalizada (figura 4), pode-se observar que, nos últimos 30 anos, essa região foi extremamente alterada. As mudanças podem ter ocorrido devido diversos fatores, desde a mudança no uso do solo, diferenças sazonais, expansão de áreas urbanas. Dentre esses fatores, está o desmatamento e as mudanças no uso do solo, que puderam ser observados no mapa (figura 4) com a comparação das imagens de NDVI de 1985 e das imagens de NDVI de 2015.

Os valores correspondentes ao NDVI, quanto mais próximos de 1, demonstram que mais densa é a vegetação. Essa característica está representada no mapa pela coloração verde escuro; já a coloração verde claro indica a presença de vegetação menos densa; e as colorações amarela e laranja mostram que há ausência de vegetação e o solo está exposto. 0 valor 0 (zero) indica que a superfície apresenta ausência de vegetação e é representado no mapa pela cor vermelha, que corresponde à presença de espelhos d'água (lagos, lagoas, açudes). Como podemos observar na área de estudo, esses espelhos d'água são, em geral, intermitentes. De acordo com a literatura, os valores de NDVI para água são negativos (WALTERS et al., 2002; SINGH et al., 2003).

Os maiores valores de NDVI correspondem aos Números Digitais (ND) mais elevados que se relacionam às áreas de vegetação com maior vigor, como se pode verificar no ano de 1985, em que o valor de NDVI estava entre 059-073, o que corresponde a uma área de $34,8 \mathrm{~km}^{2}$ com coloração verde escura, ou seja, a uma área mais conservada. Os valores mais próximos de 1, em uma área que corresponde à localização do território indígena Tapeba (ponto 1), representada pela coloração verde escuro, na parte superior direita do mapa, sentido norte (figura 3), indicam a região com vegetação nativa mais conservada ao longo dos anos de 1985 a 2015, o que corrobora pesquisas de Espírito-Santo et al. (2009) que demonstraram que a 
demarcação de terras indígenas e territórios tradicionais pode ser uma estratégia para a redução do desmatamento.

A imagem de 2015 apresenta NDVI de 0,23-0,29 e corresponde à área de 13,06 km² com baixo índice de vegetação (coloração laranja). Podemos observar que há uma área muito menor com coloração verde escura e verde claro que indica que ocorreu um avanço muito significativo do desmatamento, como situação observada também na análise visual da área. Além disso, a imagem de 2015 é do mês de agosto e, nesse período, a precipitação mensal foi de $10,4 \mathrm{~mm}$, houve diminuição do extrato herbáceo e a vegetação nativa, que é caducifólia, também pode ter interferido nos resultados do NDVI, de acordo Melo et al. (2011), e esse fator sempre deve ser observado no semiárido.

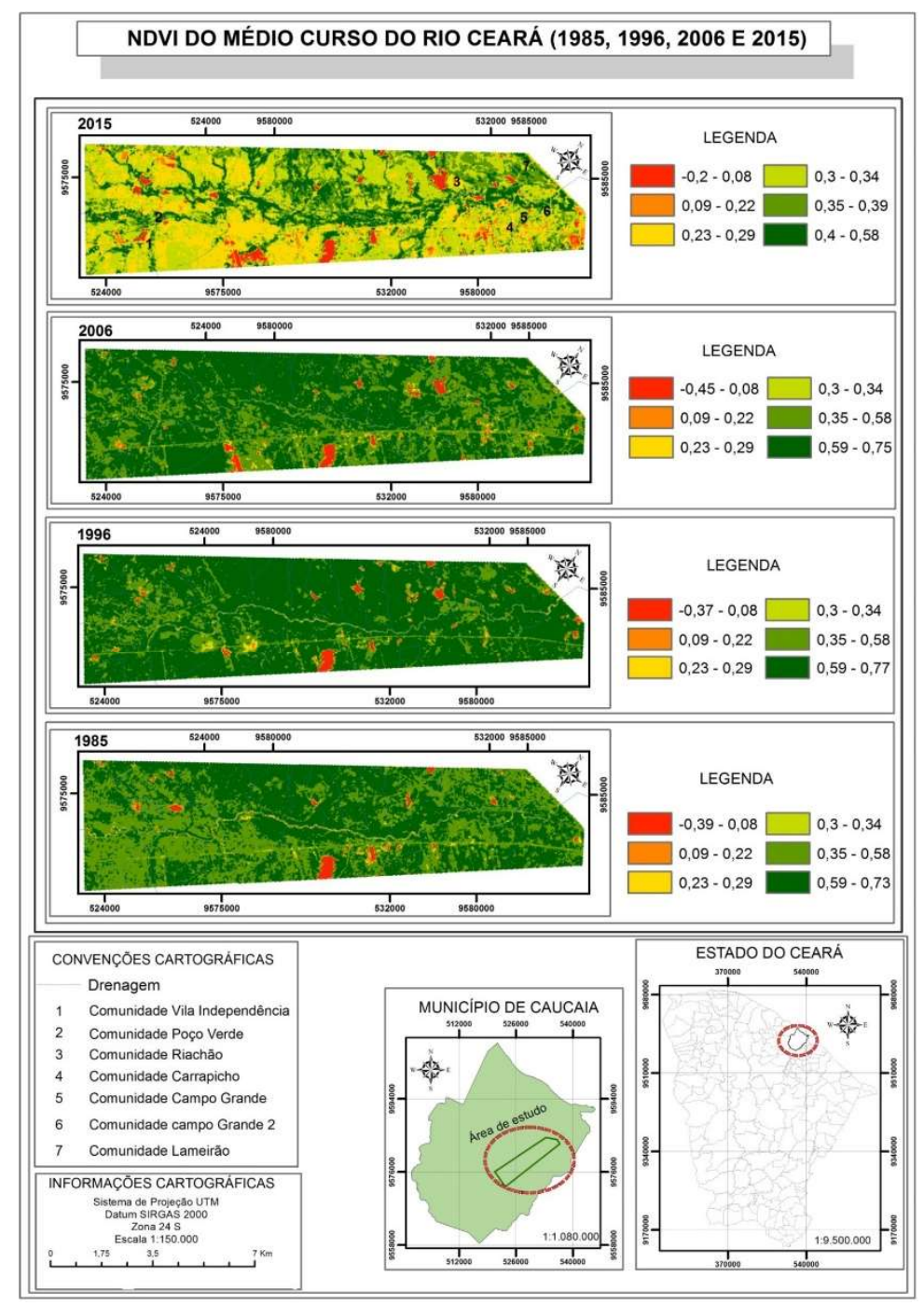

Figura 4: Mapa de índice de vegetação por diferença normalizada-NDVI.

Nesse contexto, Lourenço et al. (2017) realizaram uma pesquisa em uma área da Caatinga preservada por meio do índice de vegetação (NDVI). A área foco desse estudo foi a Bacia Experimental de Aiuaba, localizada no município de Aiuaba-Ceará, na microrregião dos sertões dos Inhamuns. Segundo esses autores, a área, mesmo sob as condições de preservação, apresenta modificações sazonais nos valores do NDVI e há uma inter-relação entre a variação do NDVI e o período ano, sendo que as alterações são reflexos da área foliar da Caatinga, e não da densidade da vegetação (figura 4). 


\section{CONCLUSÕES}

Os impactos causados pelas atividades humanas têm uma grande influência negativa no médio curso do rio Ceará. Dentre eles, observamos o avanço do desmatamento, da erosão devido à exposição do solo. $\mathrm{Na}$ análise espaço-temporal das imagens de 1985, 1996, 2006, 2015, evidencia-se o aumento das áreas degradadas: o menor índice de vegetação por diferença normalizada (NDVI) ocorre no ano de 2015.

As informações obtidas por meio da análise dos mapas de NDVI demonstram a necessidade de desenvolver ações de fiscalização, para diminuir, ou até mesmo para represar, as atividades de degradação, concomitantemente com ações de incentivo ao uso dos recursos existentes de maneira sustentável, principalmente porque ainda há utilização de determinados recursos sem a autorização dos órgãos competentes, como a extração de areia e argila.

A maior parte da superfície não possui cobertura nativa, como caracterizado no mapa de uso do solo. Essa característica é muito negativa, especialmente no que diz respeito a uma área de preservação permanente (APP) como a vegetação ciliar do rio Ceará. Cabe destacar que, nos arredores das comunidades indígenas, prevalece a cobertura vegetal em melhor estado de conservação, embora intercalada por áreas devastadas pela antropização. Dentro do território indígena, observa-se que a área de preservação permanente, como a vegetação ciliar, está mais conservada.

\section{REFERÊNCIAS}

BATISTA, C.. Avaliação do cálculo de erosividade em escala regional com o auxílio de geoprocessamento na Serra de Baturité/CE. Revista de Geociências do Nordeste, v.1, n.1, p.22-36, 2015.

BASTOS, F. H.; SILVA, E. V.. Técnicas de geoprocessamento na análise ambiental: o caso dos relevos serranos do município de Guaramiranga/CE. Revista Geonorte, edição especial, v.2, n.4, p.1743-1755, 2012. DOI: http://doi.org/10.21170/geonorte.2017

BELLUTA, I.; NEVES, R. C. F.; ZAMPIERI, F. E. S.; SILVA, R. F. B.; SARTORI, A. A. C.; ZIMBACK, C. R. L.. Aplicação de técnica de geoprocessamento em áreas degradadas de mata ciliar e sua correlação com qualidade da água numa sub-bacia hidrográfica. Irriga, Botucatu, v.16, n.2, p.193-214, 2011. DOI: http://doi.org/10.15809/irriga.2011v16n2p177

BRASIL. Código Florestal. Lei n.12.651: Dispõe sobre a proteção da vegetação nativa; altera as Leis $n^{\circ \text { s. }}$ 6.938, de 31 de agosto de 1981, 9.393, de 19 de dezembro de 1996, e 11.428, de 22 de dezembro de 2006; revoga as Leis $n{ }^{\circ}$. 4.771, de 15 de setembro de 1965, e 7.754, de 14 de abril de 1989, e a Medida Provisória no. 2.166-67, de 24 de agosto de 2001; e dá outras providências. Brasília: DOU, 2012.

CASTRO, A. S. F.; MORO, M. F.; MENEZES, M. O. T.. O Complexo Vegetacional da Zona Litorânea no Ceará: Pecém, São Gonçalo do Amarante. Acta Botânica Brasílica, Belo Horizonte, v.26, n.1, p.108-124, 2012. DOI: http://dx.doi.org/10.1590/S0102-33062012000100013

ESPÍRITO-SANTO, M. M.; SEVILHA, A. C.; ANAYA, F. C.; BARBOSA, R.; FERNANDES, W.; SANCHEZ- AZOFEIFA, A.;
SCARIOT, A.; NORONHA, S. E.; SAMPAIO, C. A.. Sustainability of tropical dry forests: Two case studies in southeastern and central Brazil. Forest Ecology and Management., v. 258, n.6, p.922-930, 2009. DOI:

http://doi.org/10.1016/i.foreco.2009.01.022

FERNANDES, A. P. B.. Estudo fitogeográfico do Brasil. Fortaleza: Stylus Comunicações, 1990.

FUNCEME. Fundação Cearense de Meteorologia e Recursos Hídricos. Índice pluviométrico no estado do Ceará. Governo do Estado do Ceará. 2016.

GASS, S. L. B.; VERDUM, R.; CORBONNOIS, J.; LAURENT, F.. Áreas de preservação permanente (APPs) no Brasil e na França: um comparativo. Confins: Revista Franco-Brasileira de Geografia, n.27, p.1-21, 2016.

IBGE. Instituto Brasileiro de Geografia e Estatística. Ceará: Caucaia: Panorama. Fortaleza, 2018.

IPECE. Ceará linformes-128. Fortaleza, 2018.

LIMA, W. P.; ZAKIA, M. J. B.. Hidrologia de matas ciliares. In: RODRIGUES; R. R.; LEITÃO FILHO; H. F.. Matas ciliares: conservação e recuperação. 2 ed. São Paulo: Universidade de São Paulo, 2000. p.33-43.

LIU, W. T. H.. Aplicações de sensoriamento remoto. Campo Grande: UNIDERP, 2006.

LOURENÇO, V. R.; RAMOS, N. N. L. A.; COSTA, C. A. G.. Distribuição espaço-temporal do NDVI sob condições de Caatinga preservada. Espaço Aberto: Revista do Programa 
de Pós-graduação em Geografia, Rio de Janeiro, v.7, n.1, p.101-110, 2017.

MARINHAS, R. V.; LACERDA, L. D.; MOUNIER, S.; PARAQUETTI, H. H. M.; MARQUES, W. S.. Caracterização hidroquímica, Distribuição e Especiação de Mercúrio nos Rios Ceará e Pacotí, Região Metropolitana de Fortaleza, Ceará, Brasil. Geochimica Brasiliensis, v.16, n.1, p.37-48, 2002.

MARTINS, R. V.; LACERDA, L. D.; MOUNIER, S.; PARAQUETTI, H. H. M.; MARQUES, W. S.. Caracterização hidroquímica, distribuição e especiação de mercúrio nos estuários dos rios Ceará e Pacoti, região metropolitana de Fortaleza, Ceará, Brasil. Geochimica Brasiliensis, v.16, n.1, p.37, 2017.

MEDEIROS, C. N.; SOUZA, M. J. N.; GOMES, D. D. M.; ALBUQUERQUE, E. L. S.. Caracterização socioambiental do município de Caucaia (CE) utilizando Sistema de Informação Geográfica (SIG): subsídios para o ordenamento territorial. Geografia Ensino \& Pesquisa, v.16, n.2, p.163182, 2012.

MELO, E. T.; SALES, M. C. L.; OLIVEIRA, J. G. B.. Diferença normalizada (NDVI) para análise da degradação ambiental da microbacia hidrográfica do Riacho dos Cavalos, CrateúsCE. Ra'e Ga, v.23, p.520-533, 2011. DOI: http://dx.doi.or/10.5380/raega.v23i0.24919

MORAES, M. V. A. R.; PORTELA, J. P.; COSTA, S. S. L.. A educação ambiental como ferramenta didática na proteção ambiental da APA do estuário do rio Ceará (CE). Revista Equador, v.4, n.2, p.36-55, 2015.

PAULA, E. M. S.. Geotecnologias aplicada à Compartimentação Ambiental da Bacia do Rio Ceará-CE. Dissertação (Mestrado em Geografia) - Universidade Estadual do Ceará, 2008.

PEREIRA JÚNIOR, L. R.; ANDRADE, A. P.; ARAÚJO, K. D.. Composição florística e fitossociológica de um fragmento de Caatinga em Monteiro, PB. Holos, Natal, v.28, n.2, p.72-84, 2012.

PIGOSSO, M.; BONFANTE, E.; FARIAS, E.; BECEGATO, V. \& ONOFRE, S. B.. Diagnóstico ambiental da bacia hidrográfica do rio Jirau alto-dois vizinhos -Paraná. Geoambiente Online, n.13, p.01-20, 2009. DOI: http://doi.org/10.5216/rev. geoambie.v0i13.25995
RIBEIRO, F. L.; SILVEIRA, G. R. P.; SANTOS, W. R. P.. Análise da preservação dos recursos hídricos por meio de imagem de satélite. Periódico Eletrônico Fórum Ambiental da Alta Paulista, São Paulo, v.11, n.5, p.11-24, 2015.

RIBEIRO, R. J. F.; JÚNIOR, D. C. C.. Delimitação das Áreas de Preservação Permanente do Município de Eunápolis - BA Utilizando Geotecnologias. Revista Científica

Multidisciplinar Núcleo do Conhecimento, n.2, v.1, p.159173, 2017.

RODRIGUES, R. R.; GANDOLFI, S.. Conceitos, tendências e ações para a recuperação de Florestas Ciliares. In: RODRIGUES, R. R.; LEITÃO FILHO, H. F.. Matas Ciliares: Conservação e Recuperação. EDUSP/FAPESP, 2004. p.235247.

SILVA, J. A. A.; NOBRE, A. D.; JOLY, C. A; MANZATTO, C. V.; RECH FILHO, E. L.; SKORUPA, L. A.; CUNHA, M. M. C. MAY, P. H. RODRIGUES, R. R.; AHRENS, S.; SÁ, T. D. A. C.. O Código Florestal e a Ciência: Contribuições para o diálogo. 2 ed. São Paulo: SBPC, 2012.

SILVA, E. V.; RODRIGUEZ, J. M. M.; MEIRELES, A. J. A.. Planejamento Ambienta e Bacias Hidrográficas. Fortaleza: UFC, 2011.

SINGH, R. P.; ROY, S.; KOGAN, F.. Vegetation and temperature condition indices from NOAA-AVHRR data for drought monitoring over India. International Journal of Remote Sensing, v.24, n.22, p.4393-4402, 2003.

TURETTA, A. P. D.. Panorama socioambiental do entorno da Central Geradora Termelétrica Fortaleza (CGTF), Município e Caucaia/CE. Rio de Janeiro: Embrapa Solos, 2007.

WALTERS, R.; ALLEN, R.; TASUMI, M.; TREZZA, R.. Surface Energy Balance Algorithm for Land (SEBAL): Advanced training and User's Manual. Boise City: Idaho Implementation, 2002.

ZANZARINI, F. V.; PISSARRA, T. C. T.; BRANDÃO, F. J. C.; TEXEIRA, D. B.. Correlação espacial do índice de vegetação (NDVI) de imagem Landsat/ETM+ com atributos do solo. Revista Brasileira de Engenharia Agrícola e Ambiental, v.17, n.6, p.608-614, 2013.

A CBPC - Companhia Brasileira de Produção Científica (CNPJ: 11.221.422/0001-03) detém os direitos materiais desta publicação. Os direitos referem-se à publicação do trabalho em qualquer parte do mundo, incluindo os direitos às renovações, expansões e disseminações da contribuiç̃o, bem como outros direitos subsidiários. Todos os trabalhos publicados eletronicamente poderão posteriormente ser publicados em coletâneas impressas sob coordenação da Sustenere Publishing, da Companhia Brasileira de Produção Científica e seus parceiros autorizados. Os (as) autores (as) preservam os direitos autorais, mas não têm permissão para a publicação da contribuição em outro meio, impresso ou digital, em português ou em tradução. 